\title{
A double-blinded, randomized, split-side, vehicle-controlled study of the efficacy of cleanser containing Acanthus ebracteatus Vahl., Suregada multiflora, and Acacia concinna in patients with atopic dermatitis: A pilot study
}

Waranaree Winayanuwattikun, ${ }^{1}$ Supenya Varothai, ${ }^{1}$ Papapit Tuchinda, ${ }^{1}$ Kanokvalai Kulthanan, ${ }^{1}$ Nuntida Prasertworonun, ${ }^{1}$ Phongphimon Dasri, ${ }^{2}$ Kwanjeera Wanichthanarak, ${ }^{2,3}$ Pravit Akarasereenont ${ }^{2,3,4}$

\section{Abstract}

Background: Barrier repair therapy is the key management approach for both eczematous and non-lesional skin of atopic dermatitis. The use of appropriate cleansers to enhance skin hydration is an adjunctive treatment that increases topical drug penetration. Anti-inflammatory properties of various medicinal plants in tropical Asia have been reported.

Objective: Investigate the efficacy of herbal cleanser containing a combination of herbal extracts from Acanthus ebracteatus Vahl., Suregada multiflora, and Acacia concinna on seemingly intact skin in patients with atopic dermatitis by measuring improvements in the skin barrier function.

Methods: This 2-week pilot study was a split-side, randomized, double-blinded, vehicle-controlled trial. All patients $(n=30)$ were asked to use both a cleanser with an active formulation containing the herbal extracts and a vehiclecontrolled cleanser on each side of mid-volar forearm. Biophysical assessments including transepidermal water loss (TEWL), skin hydration, skin $\mathrm{pH}$, and skin roughness were performed at baseline and upon study completion.

Results: Compared to baseline, the median percentage change in TEWL at the end of the study was significantly greater for the active side $10.4(-19,20.7) \mathrm{g} / \mathrm{m}^{2} \mathrm{~h}$ than the control side $-13.2(-28.7,9.1) \mathrm{g} / \mathrm{m}^{2} \mathrm{~h} ; p=0.01$. The median percentage change of skin hydration, skin $\mathrm{pH}$, and skin roughness of the active side compared to the control side had no a statistical significance.

Conclusions: This cleanser is beneficial when used as adjunctive therapy. Further studies should evaluate its antisinflammatory properties in the remedy or active phase of atopic dermatitis or other inflammatory skin diseases.

Key words: atopic dermatitis; cleanser; herbal medicine; transepidermal water loss; adjunctive therapy

\section{From:}

Department of Dermatology, Faculty of Medicine Siriraj Hospital, Mahidol University, Bangkok, Thailand

Center of Applied Thai Traditional Medicine, Faculty of Medicine Siriraj Hospital, Mahidol University, Bangkok, Thailand

Siriraj Metabolomics and Phenomics Center, Faculty of Medicine Siriraj Hospital, Mahidol University, Bangkok, Thailand

${ }^{4}$ Department of Pharmacology, Faculty of Medicine Siriraj Hospital, Mahidol University, Bangkok, Thailand

Corresponding author:

Papapit Tuchinda

Department of Dermatology, Faculty of Medicine Siriraj Hospital, Mahidol University, 2 Wanglang Road, Bangkoknoi, Bangkok 10700, Thailand

E-mail: papapitt@gmail.com

\section{Introduction}

Atopic dermatitis (AD), a chronically relapsing, inflammatory skin disease with typical morphology and age-specific patterns, affects $10-20 \%$ of children and $1-3 \%$ of adults worldwide. ${ }^{1,2}$ Genetic, immunological, and environmental factors are known to be involved in the pathogenesis of $\mathrm{AD}$. It has been suggested that skin barrier disruption is the first pathogenic mechanism of $\mathrm{AD} .^{3}$ The impaired epidermal barrier has been demonstrated to account for a disturbed lipid composition in the stratum corneum, an increase in proteolytic enzyme activities, as well as an enhancement of transepidermal water loss (TEWL). ${ }^{4,5}$ TEWL has played an important role 
in assessing the skin's barrier function. Several studies have used TEWL to monitor stratum corneum damages resulting from exposure to surfactants and have reported that TEWL had good correlation with subjective assessment of irritation. Skin barrier damage also reflects increasing TEWL in inflammatory or irritated skin. ${ }^{6}$ Abnormal skin barrier function also reflects increase in inflammatory skin. According to the methods of this study, the herbal cleanser was tested on non-lesional skin. ${ }^{7}$ Moreover, a review of the evidence obtained from previous studies found impairments of the skin barrier and minimal inflammation of the non-lesional skin of patients with AD. ${ }^{5,8,9}$ Thus, we may conclude that skin barrier improvement can reflect anti-inflammatory effect of the herbal cleanser.

Barrier repair therapy, or the prevention of a barrier dysfunction of the skin, is the key management approach for both the eczematous and the non-lesional skin of $\mathrm{AD}$ sufferers. ${ }^{8,10}$ Successful treatment needs a holistic approach, including patient education, optimal skin hydration, pharmacologic therapy, and the avoidance of triggering factors. ${ }^{11,12}$ Applying emollients to achieve the optimal hydration of the skin has taken precedence over other modes of treatment; nevertheless, the selection of a suitable cleanser is also essential for $\mathrm{AD}$ patients. Using inappropriate cleansers can irritate the skin. The surfactants used in cleansers can aggravate skin dryness and possibly interrupt the skin barrier. ${ }^{13}$ Some types of cleansers, such as detergents, can remove both foreign lipids contaminating the skin as well as naturally-occurring skin lipids; this results in the loss of natural moisturizers and facilitates the invasion of microorganisms. ${ }^{14,15}$ Moreover, cleansing the skin with alkaline soap twice daily diminishes the thickness of the stratum corneum cell layer and stimulates the loss of intercellular lipids, both of which are already declined in patients with $\mathrm{AD} .{ }^{16}$ On the other hand, gentle cleansers that can enhance stratum corneum hydration can act as an adjunctive treatment which increases topical drug penetration.

Various Thai herbal-extract formulations have been used in traditional medicine. Acanthus ebracteatus Vahl. is a mangrove plant well recognized in Southeast Asia. In Thailand, this plant has been used for the treatment of a wide range of diseases. For instance, the whole plant is boiled for use in bathing to relieve skin rashes, the fresh plant is crushed and applied on chronic wounds, and the leaf is used externally to remedy abscesses and infected wounds. ${ }^{17}$ An in vitro study of its aqueous extraction identified it has anti-inflammatory effects through its ability to reduce leukotriene $\mathrm{B}_{4}\left(\mathrm{LTB}_{4}\right)$ and thromboxane $\mathrm{B}_{2}\left(\mathrm{TXB}_{2}\right) .{ }^{18}$ The bioactive, neutral, and acidic polysaccharides found in the stem extraction of this plant have been reported for the efficacy of their immunemodulating effects on the complement system, their antitumor properties, and their antioxidative activities. ${ }^{19-21}$ Furthermore, B-sitosterol, an ingredient extracted from this plant, possesses an angiogenic function similar to the properties of Aloe vera. ${ }^{22,23}$ In both in vitro and in vivo studies, the efficacy of angiogenesis has been expressed by the promotion of wound closure.
Other widely grown plants in tropical Asia are Suregada multiflora and Acacia concinna. Suregada multiflora is a plant in the Euphorbiaceae family, and its hard wood has been used in folk medicine for the remedy of eczema, fungal skin infections, and venereal diseases. ${ }^{24}$ Its anti-inflammatory potential via the inhibition of nitric oxide (NO) and prostaglandin $\mathrm{E}_{2}\left(\mathrm{PGE}_{2}\right)$ releases has also been reported. ${ }^{25}$ As for Acacia concinna, the pod has been used as a scalp cleaner to eliminate dandruff and as an application on skin diseases. ${ }^{24}$ Moreover, the plentiful supply of saponins extracted from its pod have been found to have an effect on T-cell activities. ${ }^{26}$

Most of the aforementioned properties of medicinal plants in tropical Asia are related to immunological and anti-inflammatory activities. Therefore, our study aimed to investigate the efficacy of herbal cleanser containing a combination of herbal extracts from Acanthus ebracteatus Vahl., Suregada multiflora, and Acacia concinna on seemingly intact skin in patients with $\mathrm{AD}$ by measuring improvements in the skin barrier function.

\section{Materials and methods}

This pilot study was a 2-week, split-side, randomized, double-blinded, vehicle-controlled trial. It was performed at the Department of Dermatology, Faculty of Medicine, Siriraj Hospital, Mahidol University, Thailand, between June 2013 and August 2015.

This study was approved by the Siriraj Institutional Review Board, Siriraj Hospital, Mahidol University, Bangkok, Thailand, and written informed consent was obtained from all participants.

Thirty patients, aged 18 years or older, were enrolled. They had been diagnosed with AD using the Hanifin \& Rajka criteria, and all had been in remission or in a stable phase of the disease during the 2 weeks preceding the commencement of the study. ${ }^{27}$ We excluded patients who: (i) had used systemic corticosteroids, anti-histamines or other systemic treatments for $\mathrm{AD}$ in the 2 weeks preceding the study; (ii) had active skin lesions on the investigated area; (iii) were known or suspected to have a contact allergy to the test formulation; (iv) had a severe concomitant disease; and/or (v) were pregnant or lactating.

Each patient was asked to use both a cleanser with the active formulation (i.e., containing herbal extracts from Acanthus ebracteatus Vahl., Suregada multiflora, and Acacia concinna) and the control cleanser (i.e., identical ingredients, but without the active formulation) on each side of the mid-volar forearm. The sides of the mid-volar forearm which were to receive the cleanser with the active formulation and the control cleanser were randomized (using nQuery Advisor software, version 4.0). All test formulations were provided in identical packaging by a third party other than the investigators, so the investigators and patients were blinded to the side that used the test cleanser. The patients' mid-volar forearms were cleansed with the provided cleansers twice daily. During the study period, patients were requested to cease using any other skin care or moisturizing products on the investigated areas. Biophysical assessments comprising TEWL, skin hydration, skin $\mathrm{pH}$, and skin roughness were be evaluated at baseline and at study completion. 


\subsection{Herbal materials and formulation preparation}

The herbal cleanser was prepared by the manufacturing unit of Center of Applied Thai Traditional Medicine, Faculty of Medicine Siriraj Hospital, Mahidol University, Thailand which under Good Manufacturing Practice certification. Briefly, all materials were purchased from authorized suppliers, which recorded the source of herbal materials. The sources of herbs using in this study were collected from center and north-eastern region of Thailand. Additionally, all herbal components were cautiously authorized by two applied Thai traditional specialists and quality control staffs of the manufacturing unit using macroscopic and microscopic identification which based on plant characteristics including plant part, color, fracture, smell, and taste. The quality data of each herb and finished herbal cleanser were recorded in batch manufacturing record's document. The herbal cleanser was composed of aqueous extracts from Acanthus ebracteatus Vahl. (whole plant), Suregada multiflora (hard wood), and Acacia concinna (pod) with the ratio of 3:2:1. Other controlled ingredients, which were identical in both the active and the control cleanser, were texapon N28, amion C-02 SA (INCI: cocamide DEA), glycerine, citric acid, sodium chloride, amphitol $55 \mathrm{AB}$ (INCI: cocamidopropyl betaine), and bronidox L (INCI: propylene glycol (and) 5-bromo-5-nitro-1,3-dioxane). The quality control of aqueous extracts from Acanthus ebracteatus Vahl. have been measuring using UV-Vis spectrophotometer to evaluate the absorption or reflectance in visible light range which is the specific value of each constituent. This application is widely used in chemical analytical technique for the semi-quantitative determination as been guide from The United States harmacopeia (USP) and the European pharmacopeia ( $\mathrm{Ph}$. Eur.) guidelines. Moreover, we also use gas chromatography - mass spectrometry (GC-MS) that is a highly sensitivity and resolution analytical method to compare the atomic mass spectrum with spectrum library for identification.

\subsection{Methods of assessment}

Primary efficacy was assessed by measuring the TEWL, skin hydration, skin $\mathrm{pH}$, and skin roughness with the Tewameter TM300, Corneometer CM825, pHmeter PH905, and Visiometer SV700, respectively. All devices were from Courage and Khazaka Electronics (Colonge, Germany). Each parameter was assessed under controlled environmental conditions (temperature: $20 \pm 2^{\circ} \mathrm{C}$, and humidity: $40-45 \%$ ), according to published guidelines. ${ }^{28}$

\subsection{Statistical analysis}

SPSS Statistics for Windows, version 18.0 (SPSS Inc., Chicago, IL., USA) was used for the analysis, which was performed based on intention to treat. A $p$-value of $<0.05$ was considered statistically significant. The mean values of data at baseline and the endpoint in the active side and control side were compared using the Paired-Samples $\mathrm{T}$ Test. All values are shown as mean plus/minus standard deviation (SD). The median percentage change between baseline and the endpoint of TEWL in the active side and control side used cut point improvement more than $10 \%$ for receiver operating characteristic (ROC) with area under the curve and calculated by McNemar test. While, the median percentage change between baseline and the endpoint of skin hydration, skin pH, and skin roughness were evaluated by Wilcoxon signed rank test.

\section{Results}

A total of 30 patients with $\mathrm{AD}$ (22 females and 8 males; mean age $27.4 \pm 7.2$ years) were enrolled. Each patient received both the control and the active cleanser to apply on split sides of the mid-volar forearm. All patients completed the second-week follow up. The baseline characteristics of the patients are at Table 1. The mean SCORAD indices at baseline and the end of the study period were $20.8 \pm 13.5$ and $19.0 \pm 12.5 ; p=0.285$, respectively.

Table 1. Demographic data of 30 patients with atopic dermatitis and 11 patients who had decreasing TEWL and increasing $\mathrm{SCH}$, showing effective result.

\begin{tabular}{|c|c|c|}
\hline Characteristics & $\begin{array}{l}\text { Total }(\mathrm{n}=30) \\
\text { Number }(\%) \text {, } \\
\text { Mean } \pm \text { SD }\end{array}$ & $\begin{array}{c}\text { Good result }(\mathrm{n}=11) \\
\text { Number }(\%), \\
\text { Mean } \pm \text { SD }\end{array}$ \\
\hline \multicolumn{3}{|l|}{ Sex } \\
\hline Female & $22(73.3)$ & $7(63.6)$ \\
\hline Male & $8(26.7)$ & $4(36.4)$ \\
\hline Age (years) & $27.4 \pm 7.2$ & $27.5 \pm 7.1$ \\
\hline Age of onset (years) & $11.6 \pm 7.2$ & $14.9 \pm 5.9$ \\
\hline Age of latest episode (years) & $26.7 \pm 7.3$ & $26.7 \pm 7.2$ \\
\hline \multicolumn{3}{|l|}{ Site of onset } \\
\hline Flexural & $10(33.3)$ & $2(18.2)$ \\
\hline Non-flexural & $5(16.7)$ & $3(27.3)$ \\
\hline Both & $15(50.0)$ & $6(54.5)$ \\
\hline \multicolumn{3}{|l|}{ History of atopy } \\
\hline Allergic rhinitis & $23(76.7)$ & $6(54.5)$ \\
\hline Allergic conjunctivitis & $13(43.3)$ & $4(36.4)$ \\
\hline Asthma & $6(20.0)$ & $3(27.3)$ \\
\hline \multicolumn{3}{|l|}{ History of allergy } \\
\hline Food & $2(6.7)$ & $1(9.1)$ \\
\hline Drugs & $5(16.7)$ & $1(9.1)$ \\
\hline \multicolumn{3}{|l|}{ Previous therapy } \\
\hline \multicolumn{3}{|l|}{ Topical } \\
\hline Topical steroids & $29(96.7)$ & $10(90.5)$ \\
\hline Emollients & $15(50.0)$ & $5(45.5)$ \\
\hline \multicolumn{3}{|l|}{ Systemic } \\
\hline Antihistamines & $22(73.3)$ & $7(63.5)$ \\
\hline Prednisolone & $6(20.0)$ & $3(27.3)$ \\
\hline Phototherapy & $2(6.7)$ & $1(9.1)$ \\
\hline
\end{tabular}


Table 1. (Continued)

\begin{tabular}{|c|c|c|}
\hline Characteristics & $\begin{array}{c}\text { Total }(\mathbf{n}=30) \\
\text { Number }(\%) \\
\text { Mean } \pm \text { SD }\end{array}$ & $\begin{array}{c}\text { Good result }(\mathbf{n}=11) \\
\text { Number }(\%), \\
\text { Mean } \pm \text { SD }\end{array}$ \\
\hline \multicolumn{3}{|l|}{ Family of atopy } \\
\hline Allergic rhinitis & $15(50.0)$ & $4(36.4)$ \\
\hline Allergic conjunctivitis & $5(16.7)$ & $1(9.1)$ \\
\hline Asthma & $8(26.7)$ & $1(9.1)$ \\
\hline Atopic dermatitis & $9(30.0)$ & $1(9.1)$ \\
\hline \multicolumn{3}{|l|}{ SCORAD score ${ }^{* *}$} \\
\hline Baseline & $20.8 \pm 13.5$ & $22.9 \pm 10.3$ \\
\hline $2^{\text {nd }}$ week & $19.0 \pm 12.5$ & $17.9 \pm 7.4$ \\
\hline$P$ value & 0.285 & $0.047^{\star}$ \\
\hline \multicolumn{3}{|l|}{ Itch scale (VAS) ${ }^{\star *}$} \\
\hline Baseline & $4.0 \pm 2.9$ & $5.3 \pm 2.6$ \\
\hline $2^{\text {nd }}$ week & $2.8 \pm 2.6$ & $3.8 \pm 2.6$ \\
\hline$P$ value & $0.008^{*}$ & $0.047^{*}$ \\
\hline
\end{tabular}

* A $p$ value $<0.05$ indicates statistical significance.

** SCORAD score and itch scale were evaluated from total body lesions

SD; standard deviation, VAS; visual analog scale

At baseline, there were no statistically significant differences in any bioengineering parameters of the two sides of the mid-volar forearm (Table 2). At the end of the study, however, the mean TEWL was significantly lower for the active side than the control side $(5.44 \pm 1.58$ vs $6.13 \pm 2.44 \mathrm{~g} /$ $\mathrm{m}^{2} \mathrm{~h} ; p=0.04$; Table 2). Compared to baseline, the median percentage change in TEWL at the end of the study was significantly greater for the active side $10.4(-19,20.7) \mathrm{g} / \mathrm{m}^{2} \mathrm{~h}$ than the control side $-13.2(-28.7,9.1) \mathrm{g} / \mathrm{m}^{2} \mathrm{~h} ; p=0.01$; Table 2. The median percentage change of skin hydration, and skin $\mathrm{pH}$ of the active side compared to the control side had no a statistical significance.

In terms of skin roughness assessment using Visiometer SV700 was measured. Baseline skin roughness of active and control group was $2.20 \pm 0.51$ A.U. and $2.06 \pm 0.60$ A.U., respectively. At the end of the study, skin roughness of active group was $2.14 \pm 0.11$ A.U., while control group was $2.12 \pm$ 0.66 A.U. The level of skin roughness and wrinkling decreased from baseline on the side cleansed with the active ingredients, with a mean reduction of $-0.06 \pm 0.70$ A.U. and $-0.63 \pm 4.71$ A.U., respectively. Meanwhile, both skin roughness and wrinkling increased on the side using the control cleanser $(0.06 \pm$ 0.36 A.U. and $0.04 \pm 3.13$ A.U., respectively). Despite that, the advantages of the cleanser containing the active substances were not statistically different from the control cleanser (the related data is not shown in Table 2). The tested formulation was well tolerated, with no undesirable reactions reported by patients.

As illustrated at Figure 1, we analyzed only the side of the forearms that were cleansed with the active herbal cleanser. At the end of the study, 11 patients (i.e., 37\% of patients) had obvious improvements in their skin barrier functions, showing a reduction in TEWL and an increase in SCH. A decline in TEWL without an improvement in $\mathrm{SCH}$ was observed in 8 other patients, while a further 6 patients displayed a rise in $\mathrm{SCH}$ without any change in TEWL.

If we focus only the group of patients that had both a reduction in TEWL and a rise in SCH, patients with three sets of characteristics and clinical backgrounds (namely, young

Table 2. Bioengineering parameters of control and active groups at baseline and the end of the study

\begin{tabular}{|c|c|c|c|c|}
\hline & & \multicolumn{3}{|c|}{ Mean \pm SD } \\
\hline & & Active side & Control side & $P$ value \\
\hline \multirow[t]{4}{*}{ 1. TEWL $\left(\mathrm{g} / \mathrm{m}^{2} \mathrm{~h}\right)$} & Baseline & $5.73 \pm 1.84$ & $5.76 \pm 1.94$ & 0.88 \\
\hline & $2^{\text {nd }}$ week & $5.44 \pm 1.58$ & $6.13 \pm 2.44$ & $0.04^{\star}$ \\
\hline & $P$ value & 0.37 & 0.35 & - \\
\hline & Median percentage change (IQR) & $10.4(-19,20.7)$ & $-13.2(-28.7,9.1)$ & $0.01^{\star *}$ \\
\hline \multirow[t]{4}{*}{ 2. Stratum corneum hydration $\left(\mathrm{ug} / \mathrm{cm}^{2}\right)$} & Baseline & $36.38 \pm 6.47$ & $36.46 \pm 5.21$ & 0.88 \\
\hline & $2^{\text {nd }}$ week & $38.43 \pm 7.95$ & $37.81 \pm 8.73$ & 0.39 \\
\hline & $P$ value & 0.15 & 0.31 & - \\
\hline & Median percentage change (IQR) & $2.79(-5.44,11.07)$ & $6.19(-4.99,17.17)$ & 0.178 \\
\hline \multirow[t]{4}{*}{ 3. Skin $\mathrm{pH}$} & Baseline & $4.75 \pm 0.61$ & $4.66 \pm 0.59$ & 0.24 \\
\hline & $2^{\text {nd }}$ week & $4.58 \pm 0.44$ & $4.56 \pm 0.59$ & 0.75 \\
\hline & $P$ value & 0.13 & 0.40 & - \\
\hline & Median percentage change from 5.5 (IQR) & $20.45(13.45,24.18)$ & $19.18(11.81,22.9)$ & 0.096 \\
\hline
\end{tabular}

* A $p$ value $<0.05$ indicates statistical significance by Paired-Samples T Test.

** A $p$ value $<0.05$ indicates statistical significance by McNemar test.

$\mathrm{IQR}$, interquartile range; SD, standard deviation; TEWL, transepidermal water loss 


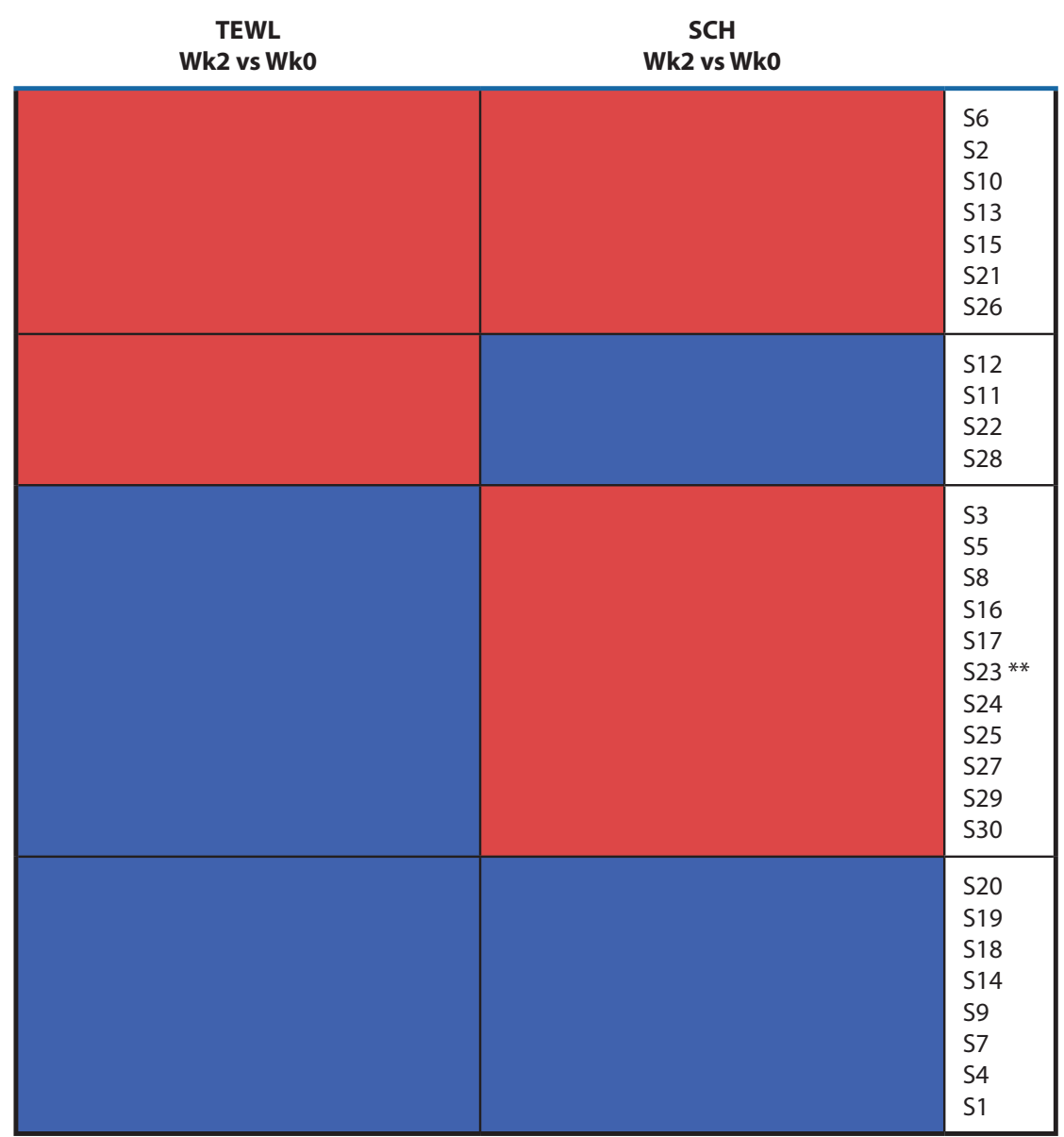

Figure 1. Heatmap representation of changes in transepidermal water loss (TEWL) and stratum corneum hydration (SCH) on the side using active herbal cleanser

Increasing and decreasing levels of TEWL and SCH after using the herbal-containing cleanser for 2 weeks are shown by red and blue colors, respectively. A group of patients with decreasing TEWL and increasing SCH are marked with asterisks (**)

versus old, male versus female, and disease severity) were observed; the related data are exhibited in Table 1. More than a half of the patients were female, with a history of lesions on both flexural and non-flexural areas. Most of them had allergic rhinitis, with a family history of atopy. Almost all had been treated with topical corticosteroids and oral antihistamines. Extremely few had undergone patch or skin prick tests in the past.

Four patients had a worsening of both TEWL and SCH. Based on their SCORAD scores at baseline and the end of the study, the diseases of those 4 were flaring up (detailed data is not presented).

\section{Discussion}

$\mathrm{AD}$, a chronic and relapsing skin disease, is one of the most common skin diseases in developed countries. It has been observed to have negative effects on the quality of life of patients as well as their socioeconomic status. ${ }^{29,30}$ A new approach termed "proactive therapy" has been proposed to alleviate those problems in patients with AD. Proactive therapy begins with topical anti-inflammatory treatment, which continues until all lesions have cured. This is followed by the intermittent application of topical anti-inflammatory drugs to the residually-affected skin, coupled with the continuous application of moisturizers on intact skin. ${ }^{8}$

The non-eczematous skin of AD sufferers has been shown to have a mild degree of inflammation compared with their lesional skin; ${ }^{31}$ their level of skin smoothness is also less than normal skin. ${ }^{32} \mathrm{~A}$ decline in epidermal lipids as well as a twofold increase in TEWL, which is indicative of an epidermal barrier dysfunction, has been evidenced in the intact skin of AD sufferers. ${ }^{5,33}$

The present study shows that the active-formulation cleanser produced improvements in the skin barrier function in the form of preservation of skin hydration and a drop in TEWL. In particular, the median percentage change in TEWL on the active side was significantly different from the TEWL on the control side ( $p=0.01$; Table 2 ). At the end of the study, the mean TEWL was also significantly lower than that for the control side ( $p=0.04$; Table 2 ). In addition, skin smoothness likely improved through a reduction in skin roughness and scaling, though the different values of improvement did not statistically outweigh those of the control side.

Anti-inflammatory efficacy through a reduction in $\mathrm{TXB}_{2}$ and $\mathrm{LTB}_{4}$ has been elucidated in Acanthus ebracteatus Vahl., ${ }^{18}$ while inhibition of $\mathrm{NO}$ and $\mathrm{PGE}_{2}$ production has been 
demonstrated as a property of Suregada multiflor. ${ }^{25}$ Polysaccharide fractions extracted from Acanthus ebracteatus Vahl. have been reported for their anti-oxidative properties. ${ }^{21}$ Furthermore, immunological adjuvant functions of the saponin substances extracted from the pods of Acacia concinna have been shown. In Thailand, the anti-inflammatory properties of Acanthus ebracteatus Vahl. are used for patients with arthritis. ${ }^{18}$

To the best of our knowledge, the efficacy of a cleanser containing aqueous extractions from Acanthus ebracteatus Vahl., Suregada multiflora, and Acacia concinna on unaffected AD skin has never previously been investigated. Thus, the heightened improvement in the skin barrier function of the active-ingredient side detected in this study is proposed as new knowledge.

After using the active-formulation cleanser on the midvolar forearm, the skin $\mathrm{pH}$ was maintained in an optimal range according to the reference range of skin $\mathrm{pH}$ for Thai patients. ${ }^{34} \mathrm{~A}$ stable and low skin $\mathrm{pH}$ has been shown to provide benefits in the form of maintaining skin barrier integrity and controlling pathogenic bacterial growth on the skin surface. ${ }^{35,36}$ Those results highlight the suitability of using the test cleanser on barrier-defective epidermis without aggravating the sub-clinical eczematous skin of patients with $\mathrm{AD}$.

The characteristics of the 11 patients who improved their skin hydration and permeability are shown in a demographic data (Table 1). Females with a history of lesions on both flexural and non-flexural areas were dominant in this subgroup, as well as a positive history of allergies. The characteristics of the patients in this subgroup did not show any unique pattern among the $\mathrm{AD}$ patients. Further studies are needed to prove the generalizability of the test cleanser.

Slow improvements in skin hydration have been found during the treatment process of $\mathrm{AD}$ with moisturizers. ${ }^{37}$ This could explain the results of the 8 patients who showed a decrease in their TEWL without an enhancement of $\mathrm{SCH}$ (Figure 1). Moreover, in a situation in which the stratum corneum is overhydrated, the level of SCH will rise, but TEWL may go up as well. Because of the reduction in the diffusional resistance of the stratum corneum layer, water flux will be enhanced. ${ }^{38,39}$ Thus, in our study, the 7 patients who possessed the most improved mean scores of SCH were also found to have an increase in their TEWL (Figure 1). Similar results have been reported in another study. ${ }^{40}$

The study by Addor et al. showed that the increase in TEWL in non-active skin lesions is correlated with AD severity; meanwhile, the more severe the $\mathrm{AD}$ clinical severity, the greater the proportional reduction in $\mathrm{SCH}^{41}$ This could explain why 4 people in the present study were detected with a worsening of the epidermal barrier function and with an exacerbation of their AD.

In summary, the test cleanser conveyed benefits when used as an adjunctive therapy during the remission phase of $\mathrm{AD}$, when there is a minimally defective skin barrier. Further studies should be conducted to assess the cleanser's anti-inflammatory properties for the remedy of the active phase of $\mathrm{AD}$ and/or other inflammatory skin diseases. At this stage, the suitability of the test cleanser for most Thai AD patients is still inconclusive; further studies with a large

\section{References}

1. Leung DY, Bieber T. Atopic dermatitis. Lancet. 2003;361:151-60.

2. Leung AK, Hon KL, Robson WL. Atopic dermatitis. Adv Pediatr. 2007; 54:241-73.

3. Elias PM, Steinhoff M. "Outside-to-inside" (and now back to "outside") pathogenic mechanisms in atopic dermatitis. J Invest Dermatol. 2008; 128:1067-70.

4. Ogawa H, Yoshiike T. A speculative view of atopic dermatitis: barrier dysfunction in pathogenesis. J Dermatol Sci. 1993;5:197-204.

5. Proksch E, Folster-Holst R, Jensen JM. Skin barrier function, epidermal proliferation and differentiation in eczema. J Dermatol Sci. 2006;43:159-69.

6. Khosrowpour Z, Ahmad Nasrollahi S, Ayatollahi A, Samadi A, Firooz A. Effects of four soaps on skin trans-epidermal water loss and erythema index. J Cosmet Dermatol. 2019;18:857-61.

7. Polanska A, Danczak-Pazdrowska A, Silny W, Jenerowicz D, Olek-Hrab K, Osmola-Mankowska A. Nonlesional skin in atopic dermatitis is seemingly healthy skin - observations using noninvasive methods. Wideochir Inne Tech Maloinwazyjne. 2013;8:192-9.

8. Wollenberg A, Bieber T. Proactive therapy of atopic dermatitis--an emerging concept. Allergy. 2009;64:276-8.

9. Danczak-Pazdrowska A, Polanska A, Silny W, Sadowska A, Osmola -Mankowska A, Czarnecka-Operacz M, et al. Seemingly healthy skin in atopic dermatitis: observations with the use of high-frequency ultrasonography, preliminary study. Skin Res Technol. 2012;18:162-7.

10. Hon KL, Leung AK, Barankin B. Barrier repair therapy in atopic dermatitis: an overview. Am J Clin Dermatol. 2013;14:389-99.

11. Krakowski AC, Eichenfield LF, Dohil MA. Management of atopic dermatitis in the pediatric population. Pediatrics. 2008;122:812-24.

12. Nicol NH, Boguniewicz M. Successful strategies in atopic dermatitis management. Dermatol Nurs. 2008;Suppl:3-18; quiz 9.

13. Cheong WK. Gentle cleansing and moisturizing for patients with atopic dermatitis and sensitive skin. Am J Clin Dermatol. 2009;10 Suppl 1:13-7.

14. Rudolph R, Kownatzki E. Corneometric, sebumetric and TEWL measurements following the cleaning of atopic skin with a urea emulsion versus a detergent cleanser. Contact Dermatitis. 2004;50:354-8.

15. Bettley FR. The Influence of Detergents and Surfactants on Epidermal Permeability. Br J Dermatol. 1965;77:98-100.

16. White MI, Jenkinson DM, Lloyd DH. The effect of washing on the thickness of the stratum corneum in normal and atopic individuals. Br J Dermatol. 1987;116:525-30.

17. Wongsatit Chuakul PS, Wichit Paonil, Rungravi Temsiririkkul, Terry Clayton. Medicinal Plants in Thailand Volume II. Amarin Printing and Publishing, Bangkok, Thailand. 1997.

18. Laupattarakasem P, Houghton PJ, Hoult JR, Itharat A. An evaluation of the activity related to inflammation of four plants used in Thailand to treat arthritis. J Ethnopharmacol. 2003;85:207-15.

19. Hokputsa S, Harding SE, Inngjerdingen K, Jumel K, Michaelsen TE, Heinze $T$, et al. Bioactive polysaccharides from the stems of the Thai medicinal plant Acanthus ebracteatus: their chemical and physical features. Carbohydr Res. 2004;339:753-62.

20. Wang JZ, Tsumura H, Shimura K, Ito H. Antitumor activity of polysaccharide from a Chinese medicinal herb, Acanthopanax giraldii Harms. Cancer Lett. 1992;65:79-84.

21. Sandoval M, Okuhama NN, Zhang XJ, Condezo LA, Lao J, Angeles FM, et al. Anti-inflammatory and antioxidant activities of cat's claw (Uncaria tomentosa and Uncaria guianensis) are independent of their alkaloid content. Phytomedicine. 2002;9:325-37.

22. Moon EJ, Lee YM, Lee OH, Lee MJ, Lee SK, Chung MH, et al. A novel angiogenic factor derived from Aloe vera gel: beta-sitosterol, a plant sterol. Angiogenesis. 1999;3:117-23.

23. Somchaichana J, Bunaprasert T, Patumraj S. Acanthus ebracteatus Vahl. ethanol extract enhancement of the efficacy of the collagen scaffold in wound closure: a study in a full-thickness-wound mouse model. J Biomed Biotechnol. 2012;2012:754527.

24. Promjit saralamp WC, Rungravi Temsiririkkul, Terry Clayton. Medicinal Plants in Thailand Volume I. Amarin Printing and Publishing, Bangkok, Thailand. 1996

25. Tewtrakul S, Subhadhirasakul S, Cheenpracha S, Yodsaoue O, Ponglimanont C, Karalai C. Anti-inflammatory principles of Suregada multiflora against nitric oxide and prostaglandin E2 releases. J Ethnopharmacol. 2011;133:63-6. 
26. Kukhetpitakwong R, Hahnvajanawong C, Homchampa P, Leelavatcharamas V, Satra J, Khunkitti W. Immunological adjuvant activities of saponin extracts from the pods of Acacia concinna. Int Immunopharmacol. 2006;6:1729-35.

27. Hanifin JM RG. Diagnosis features of atopic dermatitis. Acta Derm Venereol. 1980;S92:44-7.

28. Pierard GE, Pierard-Franchimont C, Marks R, Paye M, Rogiers V. EEMCO guidance for the in vivo assessment of skin greasiness. The EEMCO Group. Skin Pharmacol Appl Skin Physiol. 2000;13:372-89.

29. Carroll CL, Balkrishnan R, Feldman SR, Fleischer AB Jr, Manuel JC. The burden of atopic dermatitis: impact on the patient, family, and society. Pediatr Dermatol. 2005;22:192-9.

30. Holm EA, Wulf HC, Stegmann H, Jemec GB. Life quality assessment among patients with atopic eczema. Br J Dermatol. 2006;154:719-25.

31. Mihm MC Jr, Soter NA, Dvorak HF, Austen KF. The structure of normal skin and the morphology of atopic eczema. J Invest Dermatol. 1976;67: 305-12.

32. Habig J, Vocks E, Kautzky F, Ring J. Biophysical characteristics of healthy skin and nonlesional skin in atopic dermatitis: short-term effects of ultraviolet A and B irradiation. Skin Pharmacol Appl Skin Physiol. 2000;13:174-81.

33. Macheleidt O, Kaiser HW, Sandhoff K. Deficiency of epidermal protein-bound omega-hydroxyceramides in atopic dermatitis. J Invest Dermatol. 2002;119:166-73.
34. Rungsima Wanitphakdeedecha AS, Papapit Tuchinda. Transepidermal Water Loss, Hydration, $\mathrm{pH}$, and Elasticity of Skin in Atopic Dermatitis and Normal Thai Subjects. Siriraj Med J. 2005:486-90.

35. Rebell G, Pillsbury DM, De Saint Phalle M, Ginsburg D. Factors affecting the rapid disappearance of bacteria placed on the normal skin. J Invest Dermatol. 1950;14:247-64.

36. Cork MJ, Danby SG, Vasilopoulos Y, Hadgraft J, Lane ME, Moustafa M, et al. Epidermal barrier dysfunction in atopic dermatitis. J Invest Dermatol. 2009;129:1892-908.

37. Chamlin SL, Frieden IJ, Fowler A, Williams M, Kao J, Sheu M, et al. Ceramide-dominant, barrier-repair lipids improve childhood atopic dermatitis. Arch Dermatol. 2001;137:1110-2.

38. Loden $\mathrm{M}$. The skin barrier and use of moisturizers in atopic dermatitis. Clin Dermatol. 2003;21:145-57.

39. Blank IH, Moloney J 3rd, Emslie AG, Simon I, Apt C. The diffusion of water across the stratum corneum as a function of its water content. J Invest Dermatol. 1984;82:188-94.

40. Loden M, Olsson H, Axell T, Linde YW. Friction, capacitance and transepidermal water loss (TEWL) in dry atopic and normal skin. Br J Dermatol. 1992;126:137-41.

41. Addor FA, Takaoka R, Rivitti EA, Aoki V. Atopic dermatitis: correlation between non-damaged skin barrier function and disease activity. Int J Dermatol. 2012;51:672-6. 